\title{
¿Por qué no votan los salvadoreños?1
}

\author{
José Miguel Cruz
}

\begin{abstract}
Resumen
El presente artículo utiliza las encuestas de opinión pública para mostrar que el problema del abstencionismo salvadoreño no se encuentra solamente en el sistema electoral, sino en la forma en que funciona el sistema político salvadoreno en su conjunto. En tal sentido, argumenta que las razones principales para el absentismo de las últimas elecciones no son la falta de carné o los problemas del padrón electoral, sino la ausencia de cambios sustantivos en la situación del país y de los ciudadanos y en la falta de confianza en los políticos y en la mayor parte de las instituciones del gobierno.
\end{abstract}

\section{Introducción}

Los comicios generales de 1994 , calificados en su momento como las "elecciones del siglo", no pasaron de ser el primer evento electoral de la transición salvadoreña y estuvieron muy lejos de merecer el calificativo de los sufragios de la centuria. Ello, por muchas razones, pero sobre todo por el nivel de abstencionismo que privó en las mismas (ver Cruz, 1994). Para un evento de esa naturaleza, con la cantidad de puestos de gobiemo a decidir, por ser las primeras elecciones en condiciones de democratización, por incorporar a fuerzas políticas que anteriormente no tenían espacios y por no tener la amenaza de la violencia política como contexto - al menos no como en el pasado-, ese evento electoral debió haber contado con la participación de la mayor parte de la población, sin embargo, los resultados revelaron un nivel de concurrencia - para muchos- inesperadamente bajo.

Las elecciones de 1997 no se apartaron de esa tendencia y más bien la acentuaron. El evento que tomó lugar el 16 de marzo anterior puso en evidencia que la gente estuvo menos dispuesta a participar electoralmente que en el pasado; ello inclusive frente al hecho de que estas elecciones, con

1. Este artículo es un extracto de un trabajo sobre las razones del abstencionismo publicado por la Fundación Guillermo Manuel Ungo. 
todo y su carácter de trámite, tenían una cualidad novedosa en comparación con las anteriores: el resultado de las mismas, en términos de partido ganador, era incierto. Así, los comicios del año pasado sólo constituyeron un eslabón más en la aparente cadena de inasistencia electoral.

Frente a esto es necesario estudiar las razones por las cuales la población salvadoreña acude cada vez con menos frecuencia a votar en los comicios, a pesar de que éstos —en términos generalesparecen ofrecer las condiciones de competitividad y libertad mínimas necesarias. Este artículo, que constituye el resumen de un trabajo más amplio sobre el tema, se dedica precisamente a eso, a explorar las razones del abstencionismo que llevaron a la mayoría de los salvadoreños a prescindir de ejercer su derecho ciudadano específicamente en el último evento electoral, en un momento de transición política crucial para este pequeño país centroamericano. Sin embargo, esto se hace desde una perspectiva relativamente novedosa; esto es, desde la misma percepción y postura de la ciudadanía que ofrecen las encuestas de opinión pública. Con esto no se quiere negar la existencia de otros factores que contribuyen al abstencionismo salvadoreño; sin duda, el sistema electoral, las particularidades del evento y ciertas anormalidades en el mismo tienen alguna relación con el fenómeno, pero el autor - como psicólogo social- piensa que las explicaciones de la conducta social de los ciudadanos hay que buscarlas en ellos mismos, no de manera individual sino desde la perspectiva social, de su interacción con el contexto y con los diversos factores que lo rodean. En general, del conjunto que ofrece la opinión pública.

La tesis principal de este artículo es que la mayor parte del abstencionismo de los salvadoreños se explica en lo esencial por la apatía e indiferencia ciudadana a participar en el proceso electoral, y no tanto por las fallas del sistema electoral en sí mismo ${ }^{2}$. Pero, al mismo tiempo, no se niega la influencia de éstas en la estimulación y configuración de la displicencia social que ha prevalecido en los últimos eventos electorales. En otras palabras, se trata de ver al fenómeno del absentismo desde la perspectiva del comportamiento humano -de carácter social, sin duda- dejando de lado las consideraciones políticas y organizacionales del fenómeno. Al final, la apatía electoral de la población es el resultado de una compleja serie de factores, estrechamente vinculados entre sí, que van desde la percepción del desempeño de los partidos políticos hasta las irregularidades del sistema electoral, pero que en cualquier caso repercute y se expresa en la indiferencia ciudadana.

Para desarrollar lo anterior, el presente artículo se divide en cuatro apartados más. En el segundo segmento se explican, de manera breve y general, los detalles metodológicos de los sondeos de opinión pública que serán usados para explicar la conducta ciudadana. En el tercero se presenta en cifras la magnitud del problema del abstencionismo salvadoreño, su expresión y sus implicaciones sobre el sistema político, con base en la participación electoral de los años 1994 y 1997. El cuarto punto, el más importante de este trabajo, presenta e interpreta los datos de la opinión pública que ayudan a caracterizar al abstencionismo ciudadano y contribuyen a explicarlo desde la visión de los habitantes. Finalmente, se concluye haciendo una reflexión sobre las implicaciones del abstencionismo en el proceso de transición democrática del país.

\section{Las fuentes de datos}

Las encuestas que servirán como fuente de datos para buscar explicaciones y analizar el fenómeno del abstencionismo provienen esencialmente del Instituto Universitario de Opinión Pública (IUDOP), de la Universidad Centroamericana "José Simeón Cañas" (UCA), y no de otras instituciones. Todas esas pesquisas fueron hechas alrededor del proceso electoral 97: dos encuestas preelectorales, una encuesta de salida de urnas y un sondeo poselectoral. Las razones para usar sólo las encuestas del IUDOP tienen que ver con la accesibilidad de las bases de datos necesarios para el análisis preciso, la confianza en la metodología seguida para realizar las encuestas y la variedad de sondeos sobre el tema político de la que dispone el IUDOP (encuestas preelectorales, poselectorales y encuestas de salida de urnas).

2. En este punto es necesario establecer una diferencia clara entre sistema político y sistema electoral. El primero se refiere a todas aquellas normas e instituciones que conforman un régimen de conducción del poder en una sociedad; el segundo es definido por Artiga-González (1997) como el "conjunto de elementos de la normativa electoral que, con eficacia directa, conducen o inciden en la traducción o transformación de las preferencias electorales (votos emitidos) en cuotas de poder institucionalizado". 
A continuación se ofrece una breve reseña metodológica de las encuestas que realiza el Instituto Universitario de Opinión Pública de la UCA, para ubicar al lector tanto en el potencial como en las limitaciones de los datos por utilizar en este trabajo. Esta preferencia por las encuestas de la Universidad Centroamericana no descarta acudir a otras pesquisas tanto del IUDOP como de otros institutos cuando sea necesario o cuando hacerlo ayude a complementar el tópico tratado. En tales casos, se hará la referencia de la fuente en cuestión.

Las encuestas se realizan con muestras representativas -a nivel nacional- de la población adulta mayor de 18 años de edad. Esto comprende los catorce departamentos de la república salvadoreña tanto las áreas urbanas como las rurales. Las muestras totales de cada encuesta oscilan entre 1,200 -n contextos "normales", es decir, cuando no hay eleccionesy 1,800 entrevistas —en períodos preelectorales. El aumento en el número de la muestra en épocas de campaña electoral se debe a que se busca disponer de mayor variabilidad de los datos para profundizar en los análisis de la opinión pública y del posible comportamiento electoral. El error muestral usualmente se ubica en el más/menos cuatro por ciento. El procedimiento para seleccionar la muestra es politetápico: primero se define el número de encuestas por departamento, luego se divide a la población de ese departamento de acuerdo con su estrato socioeconómico. Los estratos son alto, medio-alto, medio-bajo, obrero y marginal para el sector urbano, y un solo estrato para el área rural. Definidos los estratos se hace una selección de los municipios que se visitarán en la encuesta (por lo general, los municipios más grandes como San Salvador, Santa Ana y otros se eligen por su propio peso poblacional), mientras que el resto se elige aleatoriamente. En cada municipio se hace usa escogitación de los barrios, colonias o cantones por visitar según los estratos. En cada lugar se eligen viviendas de manera no sistemática y se escoge a una persona dentro de cada vivienda, según las características señaladas en la boleta que se aplicará (cuotas de sexo y edad). Las entrevistas se hacen en forma personal en el domicilio del entrevistado. Realizadas todas las encuestas se codifican las respuestas y se procesan mediante el uso de computadoras y el programa SPSS y se procede al análisis básico de los datos.

Este es el procedimiento metodológico usual para la mayor parte de las encuestas del IUDOP. Sin embargo, algunas pueden presentar variaciones en la metodología en función del propósito o del carácter de las mismas, como por ejemplo, las encuestas de salida de urnas que parten de un universo distinto $y$, por tanto, la muestra es distinta ${ }^{3}$.

\section{La magnitud del problema del abstencio- nismo}

Para 1997 y de acuerdo con el Tribunal Supremo Electoral (TSE), en los comicios para diputados se emitieron un total de $1,176,909$ votos (el número máximo de votos); mientras que en los sufragios para concejos municipales, el total de boletas emitidas fue un poco menor: 1,169,376. A simple vista esto indica que para las elecciones de 1997 acudió a votar menos gente que en las elecciones generales de 1994, cuando votaron un total de 1,431,035 personas. ¿Cuál fue el porcentaje de abstencionismo en este último sufragio? Según un informe publicado por el Tribunal Supremo Electoral (1997), antes del 16 de marzo estaban habilitadas para votar un total de $2,679,055$ personas. Haciendo una relación con el número máximo de votos emitidos (en la elección de diputados), eso significa que alrededor del 43.6 por ciento de los ciudadanos registrados para depositar el voto lo hicieron. Ahora bien, ello implica una reducción de cerca del 10 por ciento en participación electoral en relación con las elecciones de 1994 . Sin em-

3. Para obtener más información sobre la metodología de este tipo de encuestas, así como de las regulares, se pueden consultar los informes regulares del IUDOP citados en las referencias bibliográficas de este artículo. 
bargo, no sería preciso decir acá que el abstencionismo real fue del 56.4 por ciento; de nuevo se debe tomar en cuenta la cifra de adultos que para
1997 tenian 18 años y más, y a los cuales constitucionalmente les corresponde el derecho de emitir el sufragio.

Cuadro 1

Votos emitidos por elección y porcentajes de asistencia electoral

\begin{tabular}{cccc}
\hline Año & $\begin{array}{c}\text { Total máximo } \\
\text { de votos emitidos }\end{array}$ & $\begin{array}{c}\text { \% asistencia según } \\
\text { pob. con carné }\end{array}$ & $\begin{array}{c}\text { \% asistencia según } \\
\text { pob. en edad de votar }\end{array}$ \\
\hline 1994 & $1,453,299$ & 52.8 & 49.2 \\
1997 & $1,176,909$ & 43.6 & 35.2 \\
\hline
\end{tabular}

* Se refiere a la elección de diputados.

Fuente: Elaboración propia a partir de las cifras reportadas por el Tribunal Supremo Electoral y las proyecciones de población de las Encuestas de Hogares y de la DIGESTYC.

Si se revisan las proyecciones de población para 1997 realizadas por la Dirección General de Estadísticas y Censos y otras instituciones (1996, p. 52), se puede encontrar que el total de personas en aptitud de votar en 1997 es de alrededor de $3,343,019$. Eso significa que el máximo de votos depositados el 16 de marzo de 1997 representa cerca del 35.2 por ciento de los ciudadanos aptos para sufragar. En otras palabras, en las últimas elecciones, el porcentaje de participación ciudadana real apenas superó a la tercera parte de la población y estuvo muy lejos de llegar a la mitad del total de ciudadanos que tenían el derecho de participar. El abstencionismo para 1997 se hace aún más notorio cuando se compara con las cifras del año 1994.

De todo lo anterior, que se muestra en el Cuadro 1 , se pueden hacer varias reflexiones. La primera cae por su peso y es que, desde cualquier ángulo que se vea, en 1997 votó mucha menos gente en comparación con 1994. En segundo lugar, la brecha entre la población total en edad para votar y la población con camé electoral fue mucho más grande en 1997 que en 1994. Eso significa que en las últimas elecciones muchos ciudadanos salvadoreños se quedaron -por varias razonessin el documento necesario para ejercer el sufragio, y por ello no pudieron participar en la elección de sus representantes legislativos y sus gobernantes locales. Esto obliga a intentar establecer una dimensión del impacto de la falta de documentación sobre el abstencionismo a partir de las mismas cifras del evento electoral de este año.

El total de personas en edad de votar en 1997 fue de 3,343,019; de ésas asistieron a votar hasta un máximo de 1,176,909 (en la elección de diputados). Por tanto, quedaron en total alrededor de $2,166,110$ personas sin votar en estas elecciones. Ahora bien, si se resta el total de personas que fueron a votar del número de personas con camé electoral se tiene un resultado de 1,502,146 ciudadanos que, teniendo el carné electoral, no asistieron a depositar el voto. Volviendo al total general de las personas que no votaron $(2,166,110)$, se tiene que el 69.3 por ciento de las personas que no votaron tenían el carné electoral para hacerlo, y sólo el 30.7 por ciento no poseía el documento en

4. Debe tomarse en cuenta que el carácter de las elecciones de 1994 y 1997 es distinto. Mientras que las primeras eran elecciones generales, las segundas eran sólo de diputados y concejos municipales. Eso pudo haber determinado, hasta cierto punto, el porcentaje de abstencionismo; aunque a juzgar por las tendencias desde los años ochenta, el aumento del abstencionismo estaria enmarcado dentro de una tendencia más inveterada. 
cuestión. De lo que se concluye que aproximadamente una de cada tres personas que no participaron electoralmente, no lo hicieron porque estaban inhabilitadas en términos de credencial electoral; el resto - dos de cada tres- supuestamente tenía el camé para acudir a realizar su elección política.
Ello ofrece una primera evidencia de que la mayor parte del abstencionismo no parece deberse a la imposibilidad operativa de ejercer el derecho al voto, sino a otras razones que serán exploradas más adelante por medio de las encuestas de opinión pública.

\section{Cuadro 2}

Porcentaje de representación de los partidos sobre la población total según número máximo de votos obtenidos en 1997

\begin{tabular}{lcc}
\hline Partido & $\begin{array}{c}\text { Número máximo } \\
\text { de votos válidos }\end{array}$ & $\begin{array}{c}\text { \% sobre el total de } \\
\text { población en edad de votar }\end{array}$ \\
\hline ARENA & $409,925^{*}$ & 12.26 \\
FMLN & $369,709^{\circ}$ & 11.06 \\
PCN & $102,960^{*}$ & 3.08 \\
PDC & $101,955^{*}$ & 3.05 \\
Resto de partidos+ & $162,686^{\circ}$ & 4.86 \\
\hline
\end{tabular}

Población en edad de votar $=3,343,019$.

* Obtenido en la elección de concejos municipales.

- Obtenido en la elección de diputados

+ Incluye: CD, MU, PD, PL, PLD, PRSC, PUNTO y MAS.

Fuente: Elaboración propia a partir de datos de la Junta de Vigilancia Electoral (1997) y de las proyecciones de población (DIGESTYC, et al, 1997).

Con todo, el nivel de inasistencia electoral alcanzado en el evento 97 es significativamente alto y afecta en gran medida al sistema político salvadoreño, pues provoca que las decisiones de representación política ciudadana en un momento de transición sean tomadas por sólo la tercera parte de la población en derecho - y deber- de hacerlo. Al mismo tiempo no permite que ningún partido, en el sentido estricto, sea capaz de aglutinar una proporción significativa de la ciudadanía adulta. El partido con más apoyo popular no obtiene siquiera el 15 por ciento de las preferencias de la población adulta general; más aún, la mayoría de los institutos partidarios constituidos no superan al 4 por ciento de las inclinaciones políticas, lo cual provoca una sensible incapacidad de convocatoria popular (ver Cuadro 2).

En tales circunstancias, vale la pena preguntarse las razones por las cuales la gente no participa y no vota en un evento en el cual debe elegir a sus representantes y gobernantes, considerando que la mayor parte de ella supuestamente si disponía de la documentación necesaria para hacerlo.
Esta situación plantea la necesidad de dirigir el mayor esfuerzo de búsqueda hacia la población misma, no hacia las fallas del sistema electoral, que sin duda existen y también pueden afectar la participación. En otras palabras, se trata de conocer la manera en que perciben y conciben la utilidad del proceso electoral, hacia sus actitudes y sentimientos respecto de las elecciones del 97 y cómo esto afecta su nivel de participación. Se buscan esencialmente, desde la opinión pública, las razones que hacen que los salvadoreños se queden en casa.

\section{Las razones del abstencionismo}

\subsection{Los discursos sobre el abstencionismo}

Existen dos grandes discursos a la hora de explicar el elevado abstencionismo salvadoreño expresado en las últimas elecciones. El primero sostiene que se debe, en su mayor parte, a la falta de documentación, anomalías del padrón electoral e irregularidades en el evento electoral. Esta postura fue sostenida con mucho vigor, sobre todo después de las elecciones de 1994, por algunos gru- 


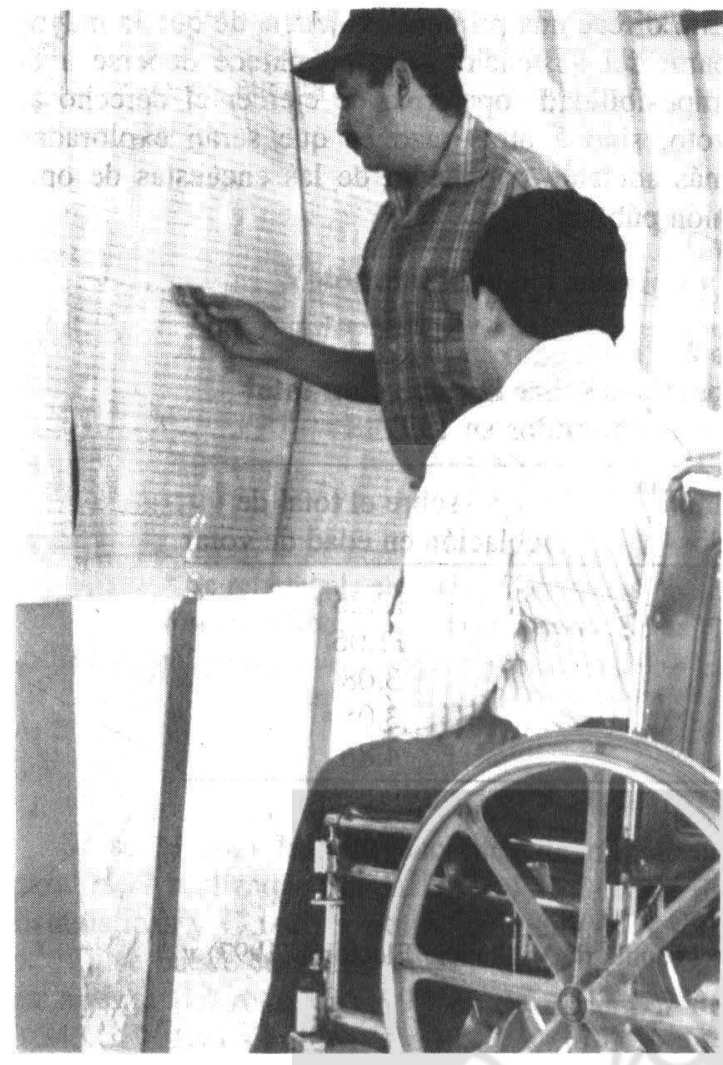

pos de la oposición. Después de marzo de 1997 y a consecuencia de las irregularidades en la última elección, esta tesis volvió a retomarse públicamente como argumento sobre la necesidad de impulsar las reformas en el sistema electoral para evitar el abstencionismo y estimular la participación ciudadana. La segunda tesis refiere que la mayor parte de la abstención se debe a la indiferencia popular hacia las elecciones y hacia la política en el país, y que las irregularidades, más que impactar de forma directa en la posibilidad de । tados si habían asistido a votar o no. La experien-

votar, lo hacen de forma indirecta pues inciden en el ánimo ciudadano para involucrarse en el proceso.

Ahora bien, sobre la primera postura ya se ha visto que la mayor parte de las personas que se quedaron sin votar supuestamente sí poseían la documentación necesaria y que sólo el 30.7 por ciento no poseía el carné necesario, eso implica que si las irregularidades y anormalidades en el día del evento electoral hubiesen imposibilitado a la mayor parte de ciudadanos a votar, éstas habrían afectado a un buen porcentaje adicional de la población apta para votar (lo que significaría que más de 650,000 personas se habrían quedado sin votar obligadamente), lo cual habría tenido un impacto devastador sobre la resolución de las elecciones y hubiese originado una disconformidad ciudadana muy grande. Con todo, sin embargo, no hay evidencias apoyadas en cifras públicas que expresen el número de personas que fueron afectadas por las irregularidades que le impidieron votars.

En cambio, las encuestas de opinión pública ofrecen indicadores que apoyan más la segunda postura. Luego de las elecciones de 1994, Cruz (1994), basado esencialmente en las encuestas preelectorales, ofreció una explicación del absentismo con base en los niveles sensiblemente bajos de interés y confianza ciudadana hacia el proceso electoral y hacia la política, y en la opinión generalizada de los encuestados de que la gente no habría de ir a votar. Para las elecciones de 1997, los sondeos precomicios de opinión pública mostraron las mismas opiniones —en varios casos con más intensidad que en 1994-, pero en esta ocasión se cuenta con un sondeo de evaluación poselectoral que parece confirmar la hipótesis de la apatía.

En esa encuesta, realizada en mayo de 1997 , se preguntó a los encuesrepresentación política ciudadana en un momento de transición sean tomadas por sólo la tercera parte de la población con derecho - y deber- de hacerlo.

5. La encuesta de salida de urnas realizada por el IUDOP en el municipio de San Salvador reportaba que no más del 4 por ciento de los votantes enfrentaron dificultades que les impidieron votar. Aunque hay razones para pensar que este porcentaje pudo haber sido más alto en el resto del país, no parecen haber bases para pensar en porcentajes mayores del 10 por ciento (ver IUDOP, 1997b). 
cia en la realización de encuestas de orden electoral enseña que la mayoría de los salvadorefíos diffcilmente aceptan de manera pública que no piensan votar, esto se aplica también cuando se les pregunta lo mismo una vez pasado el evento, en otras palabras, cuando se les consulta si votaron o no. Por ello, en el sondeo de evaluación poselectoral se buscó una formulación que facilitara la "confesión" de aquéllos que no asistieron a sufragar. Aún así, un poco más de la mitad de las personas consultadas —l 55.4 por ciento- dijeron que sí habían votado, mientras que el 44.6 por ciento reconoció que no lo había hecho (ver IUDOP, $1997 d$, p. 38). A quienes dijeron que no habían votado se les preguntaron directamente las razones por las cuales no lo hicieron. Los datos de ese cuestionamiento, tanto como de otros incluidos en el mismo sondeo, resultan muy reveladores.

La mayor parte de los abstencionistas afirmaron que no votaron porque decidieron no hacerlo o por asuntos de "índole personal"; sólo la tercera parte dijo que no había votado porque no tenía camé y un porcentaje minúsculo atribuyó su abstención a las irregularidades del evento. El Cuadro 3, basado en los resultados de la encuesta poselectoral del IUDOP realizada en mayo de 1997 , revela que el 33.3 por ciento de los ciudadanos manifestaron que no asistieron a votar por problemas personales; el 32.9 por ciento dijo claramente que decidió no hacerlo; el 29.9 por ciento arguyó que no disponía de camé, y el 3.9 por ciento dijo que efectivamente asistió a votar pero que no pudo hacerlo a causa de las irregularidades?. Hay tres aspectos de estos datos generales que es necesario comentar.

En primer lugar, el elevado porcentaje de personas que "tuvieron problemas personales" el día de las elecciones. Esta acepción usualmente se refiere a compromisos de trabajo, enfermedad propia o de familiares, responsabilidades personales, etcétera; $y$, muy probablemente, antes que revelar la cantidad de dificultades que pueden enfrentar personalmente los ciudadanos en un día tan especial como las elecciones, muestra la falta de dispo- sición de los mismos para participar en ellas. Ello porque no parece plausible que una parte tan significativa de la población, por diligencias personales, no pueda hacer un espacio en el transcurso de un día como para depositar su voto si realmente desea hacerlo. Lo anterior lleva a pensar que la mayor parte de esta gente - si no todos- en realidad no estaban interesados en participar en las elecciones y utilizaron, frente al encuestador, cualquier actividad como excusa para justificar su inasistencia.

En segundo lugar, el sondeo poselectoral señala que sólo el 3.9 por ciento de las personas no votaron porque se vieron imposibilitadas para hacerlo como producto de alguna irregularidad (lo cual concuerda con los datos obtenidos de la encuesta de salida de urnas en San Salvador). Este es, en esencia, el grupo de ciudadanos que teniendo claras intenciones de participar no pudieron hacerlo por las fallas del sistema. Así, el impacto de las deficiencias de la jomada electoral sería mucho menor del que algunos analistas han creído. De ahí que es probable que la repercusión mayor de los obstáculos electorales sea de orden psicológico más que de orden objetivo, desanimando a la gente a asistir a votar. Finalmente, los datos del Cuadro 3 serían muy coherentes con los cálculos realizados con las cifras de población en el apartado anterior: ambas fuentes señalan que alrededor del 30 por ciento de la gente no votó porque no tenía camé electoral y que, por lo tanto, la mayor parte del abstencionismo se debería a otras razones y no a la falta de la credencial.

En otro orden, el Cuadro 3 es útil también para observar las diferencias en las razones del abstencionismo según distintas variables. Las personas que ocupan los niveles más bajos de la escala socioeconómica, las mujeres, los ciudadanos de mayor edad y aquéllos que no han tenido ninguna formación educativa, en resumen, quienes están en desventaja social parecen ser los que más se vieron afectados por "problemas personales" que les impidieron asistir a votar. En cambio, la población

6. La pregunta estaba redactada de la manera siguiente: Por una u otra razón, muchas personas no asistieron a votar en las pasadas elecciones. Unos por problemas en el padrón electoral, otros por problemas personales y otros por indecisión. ¿Podría decirme si por alguna de esas razones usted dejó de votar en las elecciones del 16 de marzo pasado?

7. La misma encuesta pregunta posteriormente por las irregularidades que impidieron votar al 3.9 por ciento de los abstencionistas. Los resultados en esencia sólo señalan dos tipos de irregularidades: una es que no se encontró en las listas del padrón electoral, la otra es que algunas personas afirmaron que cuando llegaron a los lugares de votación no estaban habilitados para ejercer el sufragio. 


\section{Cuadro 3 \\ Razón por la cual el entrevistado no votó según variables (En porcentajes)}

\begin{tabular}{lcccc}
\hline Variables & \multicolumn{4}{c}{ Razones } \\
\cline { 2 - 5 } & $\begin{array}{c}\text { Por problemas } \\
\text { personales }\end{array}$ & $\begin{array}{c}\text { Decidió } \\
\text { no votar }\end{array}$ & $\begin{array}{c}\text { No tenía } \\
\text { camé }\end{array}$ & $\begin{array}{c}\text { Fue y no } \\
\text { pudo votar }\end{array}$ \\
\hline Estrato & & & & \\
Alto & 12.0 & 52.0 & 24.0 & 12.0 \\
Medio-alto & 24.5 & 45.3 & 24.5 & 5.7 \\
Medio-bajo & 27.9 & 45.6 & 26.5 & 0.0 \\
Obrero & 29.6 & 40.0 & 27.8 & 2.6 \\
Marginal & 36.5 & 25.7 & 33.8 & 4.1 \\
Rural & 40.9 & 21.7 & 33.0 & 4.4 \\
Sexo & & & & \\
Masculino & 26.9 & 41.4 & 26.4 & 5.3 \\
Femenino & 37.9 & 26.7 & 32.5 & 2.9 \\
Edad & & & & \\
18 a 25 años & 19.9 & 26.7 & 49.7 & 3.7 \\
26 a 40 años & 37.1 & 37.1 & 22.9 & 2.9 \\
41 a 55 años & 35.5 & 36.6 & 21.5 & 6.5 \\
56 años y más & 48.6 & 29.7 & 17.6 & 4.1 \\
Estudios & & & & \\
Ninguno & 56.3 & 12.6 & 27.6 & 3.4 \\
Primaria & 34.9 & 26.2 & 34.3 & 4.7 \\
Plan básico & 19.4 & 35.5 & 40.9 & 4.3 \\
Bachillerato & 28.3 & 44.3 & 23.6 & 3.8 \\
Superior & 26.9 & 52.6 & 17.9 & 2.6 \\
Todos & 33.3 & 32.9 & 29.9 & 3.9 \\
\hline ¿Por qué no voto? & & & & \\
Fuente: IUDOP (1997d), Serie de informes, No 63. & & & \\
& & & & \\
& & & & \\
\hline
\end{tabular}

que admitió directamente haber decidido no votar suele tener unas características diferentes: forman parte de los sectores socioeconómicos más acomodados, son con más frecuencia hombres que mujeres, sus edades más comunes están entre los 26 y los 55 años de edad y acusan un elevado nivel educativo. Por otro lado, la ausencia de camé electoral parece ser un factor que afectó más a los ciudadanos de los sectores marginal y campesino que al resto, más a las mujeres que a los hombres, a los más jóvenes que al resto de grupos etarios y a los sujetos con educación media en comparación con otros grupos. Estas diferencias en la forma de justificar su inasistencia electoral probablemente muestran más la mayor o menor facilidad de las personas para expresar sus actitudes hacia el evento electoral que las razones reales que les llevan al abstencionismo. Los ciudadanos que disponen de más ventajas en la sociedad salvadoreña (como ser hombres adultos medios pertenecientes a clases media y alta, con elevado nivel educativo) son más asertivos a la hora de ofrecer sus argumentos para no participar en las elecciones; en cambio, aquellos ciudadanos de menores recursos parecen ocultar más su indisposición para asistir a votar anteponiendo ciertas excusas ${ }^{\mathrm{B}}$.

8. Lo que habría que considerar acá es que la falta de carné electoral es una razón atribuible también al desgano de las personas por asistir a votar. Muchas personas no tenían la credencial simplemente porque no tenían intenciones de votar en los comicios; aparte habría que agregar a aquéllos que ofrecieron esa respuesta sólo como excusa, cuando en realidad sí tenían carné electoral. 
Ahora bien, intentando buscar explicaciones a la conducta política de los ciudadanos el pasado 16 de marzo, ¿cuál es la razón para que un poco más del 60 por ciento de las personas que no sufragaron se hayan decidido a abstenerse o hayan encontrado cosas más importantes que hacer? Este cuestionamiento se hizo tanto a aquéllos que votaron como a los que no y muestra más razones de voluntad ciudadana que de imposibilidad operativa. Un poco más de la tercera parte de los consultados, el 36.5 por ciento, dijeron que el abstencionismo se debió a que los salvadoreños "no tenían confianza en las elecciones"; el $\mathbf{1 4 . 2}$ por ciento sentenció simplemente que los conciudadanos "no habían querido asistir a votar"; otro 13.4 por ciento volvió de nuevo sobre la confianza hacia el proceso electoral. Porcentajes menores de ciudadanos mencionaron otras razones, como la falta de documentación (8.9 por ciento), miedo a la violencia (4.5 por ciento), problemas personales ( 4.3 por ciento), falta de confianza en los políticos (3.2 por ciento) y problemas técnicos (3.1 por ciento), entre otras respuestas (IUDOP, 1997a).

En el fondo, estos datos sugieren que la gente no es ajena a las razones por las cuales los demás no votan. La mayoría de salvadoreños percibirian, por tanto, un estado de desconfianza ciudadana que se expresaría claramente en la resistencia de los ciudadanos a votar. En tal sentido, comparten la idea de que la razón principal del abstencionismo está en la actitud de la gente hacia las elecciones y no tanto en los errores del sistema electoral.

\section{Figura 1}

Razones por las cuales los salvadoreños no votaron según la opinión pública

No tenían confianza en elecciones

No quisieron asistir a votar

No creían en el proceso electoral

Falta de documentación

Por miedo a la violencia

Por problemas personales

No confían en los políticos

Por problemas técnicos

Otros

No sabe

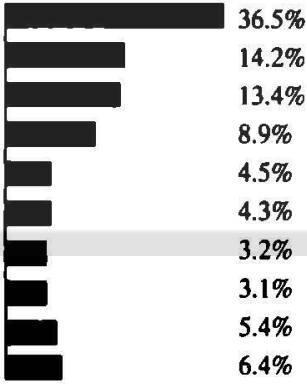

Fuente: IUDOP (1997d), serie de informes, № 63.
Lo anterior es muy útil para comprender la visión ciudadana sobre las elecciones. En todo el cúmulo de razones y opiniones que justifican el elevado abstencionismo se pueden englobar dos grandes conceptos respecto a los procesos electorales. Uno, las elecciones no logran modificar la realidad o las condiciones desfavorables de vida de muchos ciudadanos; dos, los procesos electorales -que incluye a las elecciones, los partidos políticos y al sistema electoral- no parecen ser dignos de la confianza de gran parte de la población, la gente no cree en los partidos políticos ni en los candidatos e inclusive ni en el sistema político. En tal sentido, la lógica sugiere que para entender el abstencionismo salvadoreño de los últimos años, hay que examinar esas formas de pensamiento relacionadas con la participación política electoral. El hacerlo no sólo puede traer más explicaciones

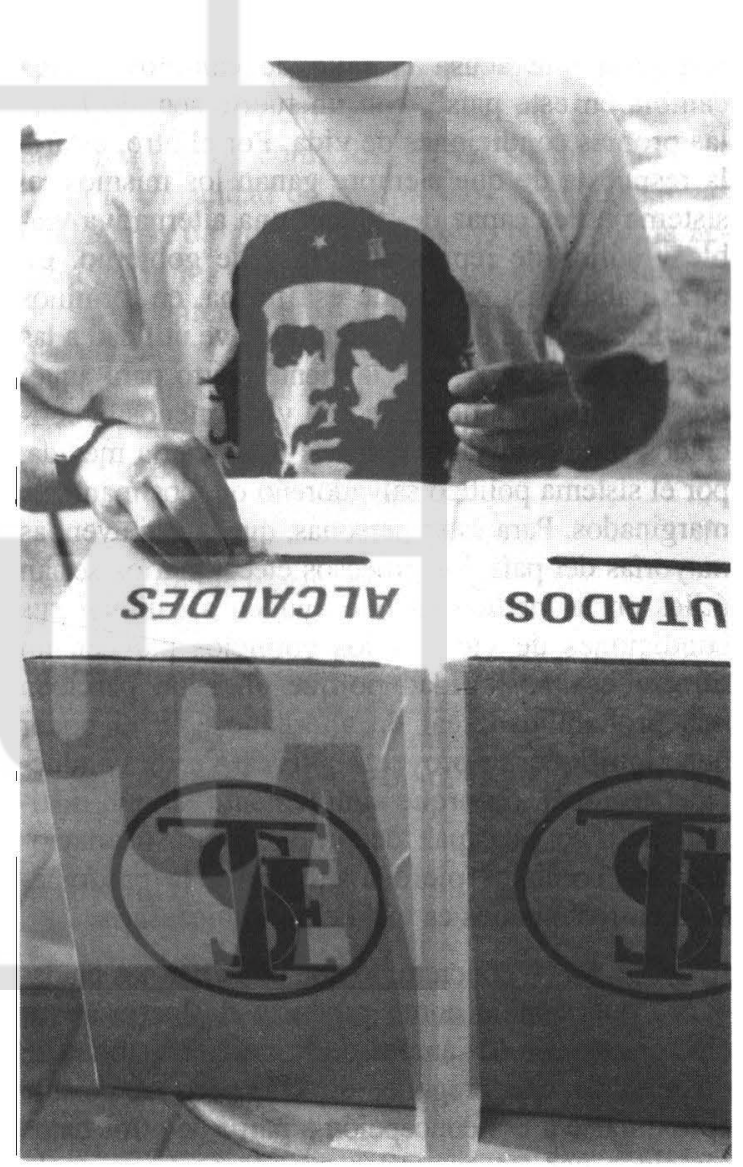


sobre la apatía electoral, sino también sobre el comportamiento político de los salvadoreños en los últimos años. A continuación, se desarrollan cada uno de esos conceptos desde los mismos datos ofrecidos por los sondeos de investigación de la opinión pública salvadoreña.

\subsubsection{La apatía electoral como respuesta a la falta de cambios}

Como ya se ha visto, buena parte de las razones de los ciudadanos para explicar la falta de participación electoral tiene relación con los efectos de los comicios: parece que detrás de la apatía electoral está la fuerte impresión de que las elecciones y, en concreto, la acción de votar, no genere un cambio sustancial en la situación del país que mejore las condiciones de vida ciudadana y/o en la correlación política que pueda hacer efectivas tales transformaciones. Por un lado estaría el tipo de respuesta que acusa la falta de cambios: "nada cambia en este país", con un fuerte sentido hacia las propias condiciones de vida. Por el otro, estaría la respuesta de que siempre ganan los mismos: el sistema no es capaz de ofrecer una alternativa viable y sólida de representación y de gobierno. En otras palabras y puesto de esa forma, en términos prácticos, mucha de esta gente no le ve utilidad a las elecciones. Esto es especialmente cierto para aquéllos que históricamente se han visto menos beneficiados por la situación del país y, en cierta medida, por el sistema político salvadoreño que los mantiene marginados. Para estas personas, que constituyen las mayorías del país, los procesos eleccionarios serían útiles en la medida en que ayuden a cambiar sus condiciones de vida; si los comicios parecen no ofrecer esa posibilidad porque ellos no perciben una probabilidad real de altemancia en el poder que signifique un proyecto alternativo de conducción nacional, o porque simplemente ningún instituto político es capaz de producir transformaciones, los comicios pierden utilidad y la participación en los mismos es vista como innecesaria.

¿Qué es, en concreto, lo que desearían los ciudadanos que cambie como producto de los procesos electorales? En los anales de la opinión pública se dispone de una pregunta directa, pero es posible aproximarse a esa concepción a partir de otros datos ofrecidos por las encuestas cuando se pregunta lo que deben hacer los nuevos gobemantes que emergen de las elecciones. Usualmente, las respuestas de las expectativas hacia los nuevos representantes po- líticos van dirigidas hacia los principales problemas del país; la mayor parte de la gente responde diciendo que los retos de los nuevos gobiemos, tanto locales como nacionales, deben ser la resolución de tales problemas. Por ejemplo, en la evaluación poselectoral de los sufragios de 1994, los salvadoreños señalaron que los retos fundamentales del siguiente gobiemo serían: combatir la delincuencia (14.6 por ciento), disminuir la pobreza (10 por ciento), crear fuentes de trabajo (9.8 por ciento) y mejorar la economía (9.3 por ciento), entre otras respuestas (IUDOP, 1997d). Esto quiere decir que, de alguna manera, lo que esperarían los ciudadanos de las elecciones es que éstas les provean de gobemantes y liderazgos políticos que sean capaces de atender los considerados principales problemas del país. Sin embargo, tres años más tarde, al evaluar los resultados de las elecciones legislativas y municipales de 1997, los ciudadanos pensaban que el gobierno en su conjunto y los nuevos representantes legislativos debían atender prácticamente los mismos aspectos que en 1994 (ver Cuadro 4). En otras palabras, habían percibido muy pocos cambios en la situación del país relacionada con el desempeño político de las autoridades nacionales como para tener unas expectativas diferentes. Los principales problemas seguían presentes.

\section{Cuadro 4}

Principales retos del gobierno luego de los procesos electorales 1994 y 1997

(En porcentajes)

\begin{tabular}{lcc}
\hline Retos del Gobierno & $\begin{array}{c}\text { Mayo de } \\
1994^{*}\end{array}$ & $\begin{array}{c}\text { Mayo de } \\
1997+\end{array}$ \\
\hline Combatir la delincuencia & 14.6 & 20.0 \\
Cumplir lo prometido & 10.8 & 2.1 \\
Disminuir la pobreza & 10.0 & - \\
Crear fuentes de trabajo & 9.8 & 26.5 \\
Mejorar la economía & 9.3 & 12.2 \\
Continuar con los acuerdos & 9.0 & - \\
Mejorar al país & 8.1 & - \\
Controlar los precios & 6.9 & 8.3 \\
Ayudar al pueblo & 6.2 & 9.3 \\
Democratizar al país & 2.0 & - \\
Combatir la corrupción & - & 3.1 \\
Resolver problemas económicos & - & 2.1 \\
Mejorar servicios sociales & - & 2.0 \\
Otras respuestas & 2.6 & 7.0 \\
No sabe, no responde & 10.8 & 7.4 \\
\hline
\end{tabular}

* ¿Cuál es, en su opinión, el principal reto que deberá enfrentar el próximo gobierno?

+ En su opinión, ¿cuál es la principal tarea que debe enfrentar el gobierno en el próximo año de gestión?

Fuente: IUDOP, base de datos evaluación poselectoral 1994; (1997d), Serie de informes, № 63. 
Todo esto se puede complementar con lo que esperan los salvadoreños de la clase política. En un sondeo sobre el sistema político realizado en octubre de 1995, el IUDOP encontró que buena parte de los ciudadanos espera que los políticos sean capaces de generar cambios. Especificamente mencionaban la ayuda al pobre, mejoría del país, capacidad para producir cambios económicos y sociales, entre otras respuestas. De tal forma que si las elecciones son vistas como la oportunidad para que los políticos lleguen al poder y puedan cumplir con las expectativas de la ciudadanía, éstas en el fondo pueden ser un mecanismo para generar cambios y cumplir con dichas expectativas. Por tanto, el salvadoreño medio probablemente valora su participación en un evento electoral con base en los alcances de las elecciones pasadas en los términos referidos anteriormente, esto es, sobre las expectativas cumplidas y no cumplidas de los mismos.

Sin embargo y de vuelta a la percepción de los ciudadanos sobre las elecciones, realmente sólo una porción de los salvadoreños han venido pensando que las elecciones son útiles para generar mejoras en el país. Es imposible saber desde cuándo los salvadoreños piensan de esa forma, aunque por ahora es posible registrarla desde las elecciones generales de 1994. Luego de esas elecciones, apenas un poco más de la tercera parte de la población, el 36.6 por ciento, sostenía que la "situación general" del país habría de mejorar, el 27.4 por ciento señalaba que seguiría igual y un 18.4 por ciento pensaba que empeoraría. En la evaluación poselectoral, realizada por el IUDOP de la UCA en 1997, se preguntó de nuevo a los ciudadanos sobre la "situación del país" después del proceso eleccionario. En esta ocasión, los resultados señalaron una actitud un poco más optimista por parte de los salvadoreños': el 41 por ciento piensa que el país va a mejorar después de los comicios; en cambio, el 26.7 por ciento cree que seguirá igual; el 13.4 por ciento inclusive sostiene que empeorará y el 18.8 por ciento no supo responder a la pregunta. Con todo, ello significa que un poco más de la mitad de la población continúa sin percibir claramente a las elecciones como una oportunidad para el mejoramiento del país.

Esto significa que si los ciudadanos no han percibido cambios sustanciales en la realidad del país y, más aún, si ni siquiera observan una modificación en la situación nacional, en la resolución de lo que ellos perciben como problemas nacionales, ello tiene un impacto muy serio sobre la concepción del beneficio de participar en los procesos electorales. Los comicios, en tal sentido, no tendrían la capacidad de cumplir con las expectativas ciudadanas de generar cambios y, por tanto, la actitud hacia los siguientes procesos estaría marcada por el desinterés que impide la participación ciudadana en los mismos. En el Cuadro 5 se presentan los datos de la encuesta de evaluación poselectoral que ofrecen evidencias de que existe cierto efecto de este tipo.

\section{Cuadro 5}

Opinión sobre la situación del país después de las elecciones según opinión sobre la utilidad de las mismas

(En porcentajes)

\begin{tabular}{lcccc}
\hline & \multicolumn{4}{c}{ Opinión sobre el futuro del paíst } \\
\cline { 2 - 5 } Utilidad de las elecciones * & Mejorará & Seguirá igual & Empeorará & No sabe \\
\hline Han sido útiles & 50.4 & 26.0 & 8.6 & 15.1 \\
No han sido útiles & 19.3 & 36.4 & 29.4 & 14.9 \\
No sabe & 22.7 & 16.2 & 16.2 & 44.8 \\
Todos & 41.0 & 26.7 & 13.4 & 18.8 \\
\hline
\end{tabular}

* ¿Cree usted que el pasado evento electoral ha sido útil para la democratización del país?

+ Después del proceso electoral ¿cree usted que la situación general del país va a mejorar, empeorar o seguira igual?

Fuente: Elaboración propia sobre las bases de datos del IUDOP.

9. Aunque desde la opinión pública, en el momento de escribir este trabajo, no hay herramientas para comprobarlo, esta leve diferencia en la visión optimista sobre el futuro del país podría estar relacionada con el hecho de que el resultado del evento electoral de 1997 fue particularmente distinto del de los procesos anteriores, pues como produc- 
En primer lugar, cruzando las opiniones de la gente sobre el futuro del país a partir de las elecciones y la utilidad de éstas para lograr la democratización del país, puede observarse de que existe cierta relación entre ambos pensamientos (ver Cuadro 5). Casi la mitad de los salvadoreños que piensan que las elecciones han sido útiles opinan también que la situación general del país mejorará; el 26 por ciento cree que seguirá igual y sólo el 8.6 por ciento sostiene que empeorará; en cambio, los porcentajes de las opiniones negativas sobre la utilidad de las elecciones se distribuyen de forma distinta, y muestran simultáneamente más peso de las opiniones críticas hacia el futuro del país: solamente el 19.3 por ciento de quienes piensan que el proceso electoral no ha sido útil creen que el país va a mejorar después de los comicios; el 36.4 por ciento afirma que seguirá igual y el 29.4 por ciento sostiene que la "situación general del país" empeorará. En otras palabras, los ciudadanos que tienden a encontrarle utilidad a las elecciones suelen tener una visión más optimista sobre el futuro del país como producto del proceso eleccionario; mientras que aquéllos que no le encuentran utilidad o provecho a las elecciones, comparten una visión un poco más crítica sobre lo que pasará en el país como efecto de los resultados de las elecciones. Estos datos muestran, por tanto, una notable coherencia en la percepción y las opiniones de los salvadoreños acerca de las elecciones de 1997.

\section{Cuadro 6 \\ Nivel de beneficio percibido de las elecciones según participación en las mismas}

\begin{tabular}{l|c}
\hline $\begin{array}{l}\text { Participación } \\
\text { electoral en 1997 }\end{array}$ & $\begin{array}{c}\text { Nivel beneficio percibido } \\
\text { de las elecciones }\end{array}$ \\
\hline Sí votó & 4.59 \\
No votó & 4.09 \\
\hline
\end{tabular}

$F=32.12 ; p<0.0001$

Fuente: Elaboración propia.
Todo ello da pie, en segundo lugar, a que de la unión de estas opiniones pueda conformarse una variable que ayudará a expresar el nivel de beneficio que los ciudadanos vieron en los comicios celebrados en $19971^{10}$. De acuerdo con este ejercicio, las personas que asistieron a elegir a sus representantes legislativos y a sus gobernantes locales percibirían mucho más beneficio de las elecciones que aquéllas que se abstuvieron. El Cuadro 6 revela diferencias que tienen significación de orden estadístico, es decir, que no se deben al azar o a un efecto casual, sino al efecto de pertenecer al grupo de los votantes o los no votantes. Es decir, las personas que participaron electoralmente se diferencian de manera significativa de las que no lo hicieron porque poseen un conjunto de opiniones más positivas sobre el beneficio y la utilidad de las elecciones. Los abstencionistas, en este sentido, tendrían una visión menos optimista del efecto de las elecciones sobre la vida nacional y esta forma de ver los procesos electorales incidiría sobre la decisión y la conducta de los ciudadanos que les lleva a retirarse de los comicios.

Ahora bien, como ya se ha sugerido anteriormente, esta motivación para abstenerse, la de no ver utilidad en las elecciones, toma sentido en la medida en que los ciudadanos han advertido que los repetidos procesos eleccionarios no traen modificaciones sustanciales a su vida y/o a la del país. Esto es especialmente cierto cuando la población está a la espera de tales cambios porque sus condiciones de vida son muy precarias, o porque la situación del país le parece especialmente desventajosa para ella. Así parece ser, sobre todo, para los más pobres y quienes poseen menos formación educativa. Las elecciones no traen el cambio esperado y, por ello, no se encuentran razones para involucrarse en ellas. Esto, por supuesto, no ocurre de la noche a la mañana. Es parte de todo un proceso en el que la gente anteriormente participaba en los eventos electorales - sobre todo entre 1982 y 1985 - (ver Baloyra-Herp, 1995) y esperaba que con ello se produjeran los cambios ne-

to de estas últimas elecciones, el partido de gobierno cedió significativas cuotas de poder en el terreno municipal y legislativo, las cuales pasaron a manos del FMLN. En todo caso, ésta sería una interesante hipótesis que se desprendería de la tesis del abstencionismo electoral como producto de la falta de cambios en el país. Las elecciones de 1997, que aparentemente sí han representado un cambio al menos en términos de alternancia en el poder municipal y legislativo, podrian significar el paradigma esperado para que algunos se decidan a participar electoralmente.

10. La variable se cré́ sobre la lógica de una escala continua, donde el valor mayor (6) expresa el mayor nivel de beneficio que los ciudadanos ven en las elecciones, mientras que el puntaje menor (0) muestra el menor grado de ganancia que perciben de los sufragios. El promedio general de la escala fue de 4.37, más cerca de una opinión 
cesarios para resolver los males históricos, cuando esto no ocurrió de la forma en que se esperaba, las elecciones comenzaron a abandonarse (ver Cruz, 1995; Coleman, Cruz y Moore, 1996; IUDOP, 1996)".

Con todo, parece claro que la opinión de muchos ciudadanos - tanto abstencionistas como votantes- sobre el abstencionismo como producto de la incapacidad de las elecciones para generar cambios, tiene un fundamento desde la concepción pública de la realidad política salvadoreña. En otras palabras, no se trata de un argumento más o de una opinión superficial sobre un fenómeno que es evidente a toda la población; la mayor parte de datos, de los que se disponen en las pesquisas, senalan que esas opiniones parten de una percepción que forma parte de un sistema de pensamiento que es relativamente amplio y coherente sobre la situación política salvadoreña. Sin embargo, este argumento es sólo una parte de ese sistema de percepción y pensamiento. En realidad, éste se complementa con el otro argumento mayoritario sobre el abstencionismo, esto es, que los salvadoreños no encuentran opciones viables de elección porque no poseen la suficiente confianza en la clase política que les impulse a participar electoralmente.

\subsubsection{El abstencionismo como producto de la falta de confianza en los políticos}

Uno de los principales argumentos de los abstencionistas, y de las personas que juzgan las razones de la poca participación ciudadana, resalta el hecho de que una parte importante de la ciudadanía no encuentra un instituto partidario que llene sus expectativas políticas; esto se expresa cuando dice que "ningún partido le parece", "no confía en los partidos", "no cree en los políticos" e, inclusive, en términos más abstractos, que "no confía en el sistema electoral" (ver Figura 1). En tal sentido, mucha gente en edad de participar en los procesos eleccionarios dejaría de votar porque no confía en absoluto en el sistema político con lo que ello implica: candidatos, partidos, sistema electoral, etcétera. Ello, sin duda, se relaciona con el discurso anterior: el poco rendimiento de las elecciones para generar cambios significativos en la realidad. Dicho de otra forma, los ciudadanos no confían en el aparato electoral y no creen en las opciones políticas que participan en ellas porque, históricamente, han aprehendido que éstos no responden eficientemente a las necesidades de cambio social que está reclamando la población ${ }^{12}$. Sin embargo, la falta de confianza en los partidos y el sistema y la ausencia de alternativas políticas aceptables se han constituido en una razón en sí misma, y cuando varios salvadoreños se abstienen de votar en los procesos electorales, justifican su conducta al señalar la falta de fe en las opciones que ofrece el sistema.

En todo caso, la falta de confianza en los partidos políticos, en los candidatos e inclusive en el sistema electoral es algo que ha sido repetidamente consignado con claridad por las encuestas de opinión pública desde las elecciones de 1994 (IUDOP, 1994). A través de los años, las pesquisas que recogen el pensamiento popular han venido registrando que los ciudadanos salvadoreños cada vez creen menos en los partidos políticos. En octubre de 1995, un poco más del 75 por ciento de la población adulta del país, esto es, tres de cada cuatro habitantes, tenia poca o ninguna confianza en los partidos políticos, constituyéndose en las instituciones nacionales que recogían los más bajos nive-

positiva que negativa, esto porque la opinión sobre la utilidad de las elecciones era singularmente muy positiva. Sin embargo, el valor de la escala puede ser sometida a pruebas estadísticas que permitan establecer diferencias en la forma de ver a las elecciones por parte de aquéllos que votan frente a los que se abstienen.

11. Pero, quizás, el impacto mayor contra las elecciones vino paradójicamente de los acuerdos de paz. Estos demostraron que uno de los problemas esenciales del país pudo solucionarse sin pasar directamente por un evento electoral.

12. Hay que reiterar aqui que, según las ovidencias que aportan las encuestas, esas necesidades de cambio se limitarían a la resolución de los principales problemas nacionales. 
les de confianza popular, muy por debajo del órgano de justicia, la presidencia de la república y aún más de la Procuraduría para la Defensa de los Derechos Humanos o la Policía Nacional Civil. Algo más de un año más tarde, en febrero de 1997 y en vísperas de los comicios municipales y legislativos, las opiniones se habían modificado un poco: el 65.5 por ciento de las personas en edad de votar conservaban poca o ninguna confianza en los partidos políticos, y sólo el $\mathbf{8 . 7}$ por ciento tenía mucha confianza en los mismos, pero éstos seguían siendo los institutos que atraían los menores niveles de certidumbre popular.

\section{Figura 2}

\section{Porcentaje de personas que no revelaron} su intención de voto entre 1994 y 1997

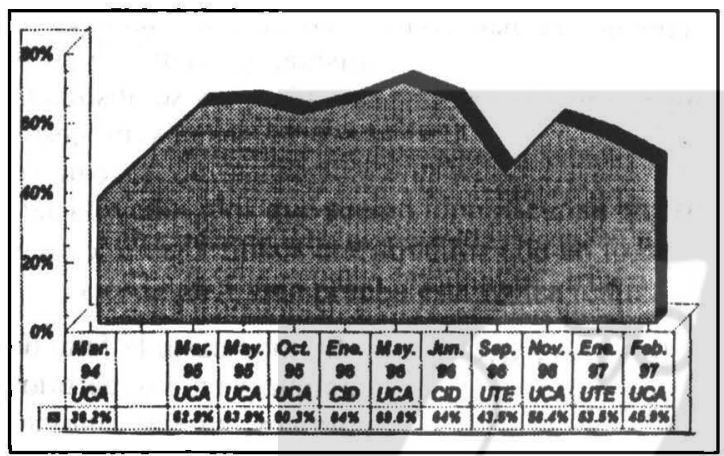

Fuente: Elaboración propia según encuestas del IUDOP, UTEC y CID.

Pero uno de los mejores indicadores del impacto que tiene la falta de credibilidad de los partidos políticos sobre la participación electoral, se puede encontrar en los mismos datos sobre intención de voto que registraron las encuestas de opinión pública de cara a las elecciones. Precisamente uno de los resultados más recurrentes de todos los sondeos de opinión pública de carácter político, realizados entre marzo de 1994 y febrero de 1997, es el que mostraba que la mayor parte de la población no revelaba su partido político de preferencia cuando se les preguntaba por ellos (ver Figura 2). Varias personas contestaron que tal información era "secreta" y aludiendo a su derecho a mantener en reserva sus opciones políticas se oponian a brindar su posible opción de voto. No obstante, la mayoría de los consultados respondían que no tenían un partido de preferencia o que no sabían por quién votarian. Luego de las elecciones de 1994, la sumatoria de los porcentajes de las personas que no revelaban su opción política fue siempre superior al porcentaje de personas que sí elegían un instituto político. En la Figura 2 puede verse que en la mayoría de sondeos realizados en la época "interelectoral", el total de personas que no revelaban su voto era mayor al 50 por ciento de los ciudadanos, porcentaje que parece reducirse al acercarse los sufragios.

Es interesante ver cómo, en la práctica, la falta de definición de una opción de voto o la ausencia de partidos de preferencia en época preelectoral, está fuertemente vinculada a los bajos niveles de credibilidad que pueden recibir los partidos políticos. Con las respuestas a la pregunta sobre la confianza en los partidos políticos, para construir una escala de confiabilidad en los mismos y cruzarla con las respuestas sobre las preferencias políticas y la intención de voto, es posible advertir que los niveles de credibilidad con que son vistos los partidos políticos están relacionados con la posibilidad de elegir o no un partido político ${ }^{13}$.

\section{Cuadro 7}

Nivel de confianza en los partidos políticos según partido de preferencia y opción de voto

\begin{tabular}{lc}
\hline Pregunta & $\begin{array}{c}\text { Nivel confianza } \\
\text { en partidos }\end{array}$ \\
\hline ¿Cuál es su partido preferido?* & 2.11 \\
Eligió partido & 1.66 \\
Ninguno & \\
\hline ¿Por qué partido votaría para diputados?+ & 2.03 \\
Eligió partido & 1.79 \\
Voto secreto & 1.71 \\
No sabe & 1.27 \\
\hline Ninguno & \\
\hline
\end{tabular}

* $F=86.41 ; p<0.0001$

$+F=33.05 ; p<0.0001$

Fuente: Elaboración propia sobre la base de datos del IUDOP.

13. Para realizar esto, las respuestas sobre la confianza en los partidos políticos se convirtieron en una escala del 1 a 4, en la que se asignó uno de estos valores a cada una de las respuestas: nada de confianza (1), poco de confianza (2), algo de confianza (3) y mucha confianza (4). Así, un promedio cercano al 1 significaría descon- 
Según el Cuadro 7, los salvadoreños que suelen identificar su partido de preferencia poseen mucha más confianza en los institutos políticos que aquéllos que no lo hacen. Esta diferencia entre ambos grupos no se debe a una casualidad; una prueba estadística realizada con esos datos comprueba que existe cierta relación entre ambas variables. Lo mismo sucede cuando se trata de la intención de voto partidista —en el caso de la elección para la asamblea legislativa-, las personas que señalaron al partido por el cual pensaban votar en las elecciones presentan el promedio más elevado de confianza en los partidos, en comparación con aquéllos que no declaran su intención de voto, ya sea porque no quieren hacerlo o porque no sabían por quién votarían. En este punto, las cifras del Cuadro 8 parecen confirmar la tesis de que es posible encontrar diferencias inclusive entre las personas que no declaran por quién votarán. Los ciudadanos que dijeron que no votarían por partido alguno tienen menos confianza en los partidos que quienes afirmaron que no sabían por cuál votar, y mucha menos confianza si se compara con aquéllos que responden que el "voto es secreto". Sin embargo y a pesar de las diferencias entre las personas que no declaran su intención de voto, sin duda en términos de confiabilidad partidista, éstas personas se encuentran más cerca entre sí que lo que están de los que sí han hecho su selección política.

Lo anterior puede parecer muy lógico, pero la utilidad de mostrarlo de esta forma radica en que pone de manifiesto con claridad el peso de la confianza que los ciudadanos tienen en los partidos políticos a la hora de elegir y, en consecuencia, en el momento de decidirse a participar electoralmente. De tal forma que no basta que existan partidos que ocupen todo el espectro político-ideológico, como tampoco basta que el sistema electoral funcione medianamente bien para que la gente se decida a participar. Los datos recogidos por las pesquisas de opinión pública ponen de manifiesto la importancia del papel de los partidos para que los salvadoreños se decidan a asistir a votar. Si un sistema político no posee partido alguno que sea capaz de atraer para sí un grado mínimo de confianza ciudadana — como el salvadoreño- porque los institutos no han sido capaces de responder a las demandas de la población, éste sistema tendrá que enfrentar un serio problema de participación civil en sus plebiscitos que, más temprano que tarde, podría redundar en la ausencia de respaldo popular hacia los representantes y gobernantes elegidos, y con ello extender la desconfianza hacia otras instancias del sistema electoral.

\section{Figura 3}

Ciudadanos con mucha confianza

hacia aspectos de las elecciones de 1997 Datos de diciembre de 1996

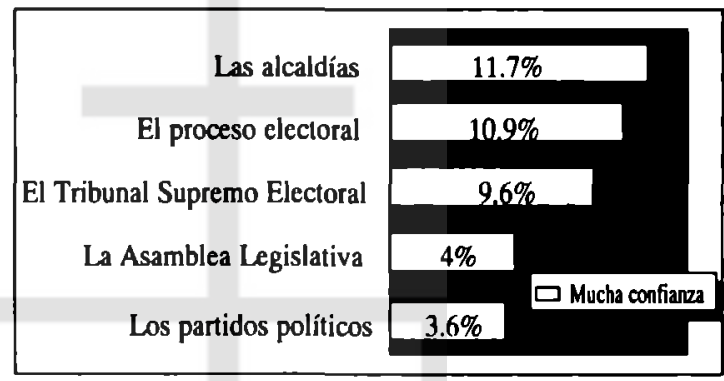

Fuente: IUDOP (1996), Serie de informes, № 60 .

Precisamente, en el caso salvadoreño, la desconfianza hacia los partidos políticos no parece venir sola. La Figura 3, basada en los resultados de la encuesta realizada por el IUDOP en diciembre de 1996 , antes de que diera inicio la campaña electoral, muestra que el problema de la desconfianza en los partidos políticos no se encuentra aislada de los niveles de credibilidad que deben enfrentar otras instancias relacionadas con el proceso eleccionario de 1997. Aunque puede observarse que los partidos políticos registran los menores niveles de confianza de la población, el mismo proceso electoral, el tribunal de elecciones y las mismas instituciones que habrían de ser sometidas a relevo a través del proceso, no reciben unos niveles de confianza que puedan considerarse grandes. De hecho, para finales de 1996, todas las instituciones, incluido el mismo proceso electoral, no reunían más del 12 por ciento de credibilidad. Como ya se ha señalado más arriba, los salvadoreños probablemente no sólo pensaban que carecían de opciones por la poca confianza que les merecen los partidos políticos, sino que además pensaban ya que

fianza en los institutos partidistas, mientras que el 4 representaría el nivel más alto de confianza en los partidos. El promedio general fue de 1.82 , lo cual mostró o reconfirmó el bajo nivel de credibilidad que tenían los partidos cuatro meses antes de las elecciones del 16 de marzo. 
muchos de los aspectos relacionados con el sistema electoral tampoco eran de fiar en su totalidad.

En este sentido, la desconfianza de muchos de los ciudadanos hacia los partidos políticos es parte de una desconfianza más generalizada sobre el sistema electoral, lo cual tiene un decidido impacto en la conducta de asistir a votar, pues acumula condiciones y razones para que la gente desista de la participación. Las personas que no encuentran un partido político de preferencia, por la falta de confianza que tienen en tales institutos, son también las que suelen mostrar los mayores niveles de desconfianza en otras instituciones o a las que el sistema electoral no les merece ninguna credibilidad. La contribución de la desconfianza ciudadana en el proceso electoral en la participación popular puede verse también con los datos de las pesquisas con las que se dispone en este trabajo.

En las diversas encuestas electorales se preguntaba a los ciudadanos sobre la confianza que le merecía el proceso electoral para elegir alcaldes y diputados. Los resultados mostraron una tendencia interesante: la confianza en las elecciones aumentó conforme se acercaron las elecciones, pero, además, la evaluación poselectoral arrojó un nivel de confianza más positivo que el que había prevalecido durante la época preelectoral ${ }^{14}$ (ver Cuadro 8). Sin embargo, la confianza recogida el mismo día de las elecciones, introduce una evidencia crucial sobre el peso de la confianza en la participación ciudadana. Los datos que se refieren al día de las elecciones (tercera columna de porcentajes del cuadro en cuestión) se recogieron de una encuesta de salida de umas realizada en los mismos centros de votación; esta encuesta, a diferencia del resto, reúne a las personas que sí asistieron a votar y no a toda la población, por lo tanto, se espera y es lógico que estas personas presenten un mayor grado de confianza en el proceso. Es más, la encuesta de evaluación poselectoral revela que aunque después de las elecciones los niveles de credibilidad en el proceso son un poco más positivos que los de febrero antes de las elecciones, éstos - los grados de confianza popular - no se asemejan mucho a los recogidos el 16 de marzo entre los electores.

\section{Cuadro 8}

Confianza en el proceso electoral de 1997 en distintas fechas de consulta (En porcentajes)

\begin{tabular}{lcccc}
\hline \multirow{2}{*}{$\begin{array}{l}\text { Nivel de } \\
\text { confianza }\end{array}$} & \multicolumn{4}{c}{ Fecha del sondeo } \\
\cline { 2 - 5 } & Diciembre 96 & Febrero 97 & 16 de marzo 97* & Mayo 97 \\
\hline Nada & 24.1 & 20.6 & 7.4 & 15.6 \\
Poca & 34.7 & 29.9 & 26.0 & 27.8 \\
Algo & 27.1 & 28.6 & 33.0 & 38.7 \\
Mucha & 10.9 & 17.2 & 35.6 & 18.0 \\
No responde & 3.2 & 3.6 & 1.8 & 0.8 \\
\hline
\end{tabular}

* Datos obtenidos con votantes activos del municipio de San Salvador.

Fuente: IUDOP (1996), Serie de informes, № 60; IUDOP (1997a), Serie de informes, № 61; IUDOP (1997b), boletín de prensa 2; IUDOP (1997d), Serie de informes, № 63.

Con todo, la revisión de los sondeos electorales del IUDOP revela que cierta porción de la gente fue aumentando sus niveles de confianza en el proceso electoral (aunque los niveles de confianza nunca llegaron a ser decididamente altos) pero, sobre todo, revela que, en cualquier caso, la confian- za de la población general por las elecciones es muy distinta de aquella confianza mostrada por las personas que acudieron a votar el 16 de marzo en el municipio de San Salvador. Es decir, los votantes tenían más confianza en el proceso que los salvadoreños medios. Para fortalecer esta tesis, se

14. Acá habria que considerar que la confianza en el proceso electoral, una vez realizado éste, no se compara con las mediciones pre-electorales porque, sin duda, hay un efecto claro del resultado de las elecciones en el juicio ciudadano. 
acudió también a la base de datos de la evaluación poselectoral y se compararon los niveles de confianza en las elecciones entre quienes afirmaron que participaron en los comicios y los que se abstuvieron ${ }^{15}$. Los resultados, mostrados en el Cuadro 9 , son muy claros. Mientras que las personas que votaron presentan un nivel de confianza mayor al promedio general, los ciudadanos que se abstuvieron exhiben un indicador menor de confianza. Estas diferencias pueden parecer leves - al fin y al cabo ambos grupos registran un nivel de confianza que ronda el promedio que es $2.59-$, sin embargo, una prueba estadística de diferencia de medias certifica que tal disparidad es significativa como para pensar en un efecto relacionado con la pertenencia al grupo de los votantes o los no votantes. Dicho de forma más clara, las personas que asistieron a votar tuvieron más confianza en el proceso electoral que aquéllas que no votaron, lo cual podría estar confirmando dos cosas: una, que el nivel de credibilidad que los ciudadanos tenían en el proceso de 1997 ha sido también una variable fundamental para decidir la participación en tal evento; dos, que la falta de credibilidad en las elecciones es parte de un sistema de pensamiento social más amplio que incluye la desconfianza en los partidos políticos y, probablemente además, en el sistema político salvadoreño.

Cuadro 9

Nivel de confíanza en las elecciones según participación electoral

\begin{tabular}{l|c}
\hline $\begin{array}{l}\text { Participación } \\
\text { electoral en } 1997\end{array}$ & $\begin{array}{c}\text { Nivel de confianza } \\
\text { en las elecciones }\end{array}$ \\
\hline
\end{tabular}

\begin{tabular}{l|l} 
Sí voto & 2.83 \\
No votó & 2.28 \\
\hline
\end{tabular}

$\mathrm{F}=105.23 ; \mathrm{p}<0.0001$

Fuente: Elaboración propia.

Las implicaciones de lo anterior son muy grandes. En el fondo, los datos de los que se dispone para efectuar este trabajo sugerirían que los niveles de confianza que tiene la mayoría de la población -que es la que no votó- en el proceso electoral de 1997, no han sido lo suficientemente altos como para decidir una significativa participación electoral. Además, todos los datos sugieren que el problema de la desconfianza ciudadana es un asunto que va más allá de la ausencia de seguridad hacia las opciones políticas disponibles, el fenómeno es mucho más complejo. Parece que lo que impide que los ciudadanos participen electoralmente es una profunda actitud de incredulidad hacia todo lo que tiene que ver con la política del país. Anteriores estudios han mostrado que la falta de participación eleccionaria se correlaciona fuertemente con la ausencia de interés y participación en la política de manera más amplia (ver Cruz, $1994 ; 1995)$. Las personas que no votan son también las que no forman parte de otro tipo de organizaciones, no se inmiscuyen en la política e inclusive no se informan de lo que sucede políticamente.

Este fenómeno que afecta el comportamiento político ciudadano no parece haberse revertido en las elecciones municipales y legislativas de 1997; más aún, está claro que la conducta de absentismo aumentó. A pesar de lo competitivos que pudieron haber sido estos sufragios y aunque en esta ocasión las pesquisas de opinión pública registraron un aumento en el interés civil por el proceso, la desconfianza fundamental en todo el sistema se mantuvo y esto, al final, tuvo más peso y aportó decididamente a la conducta de abstención de los salvadoreños.

Ya se ha dicho que junto a esta desconfianza reside la percepción de que la clase política no ha sido capaz de generar los cambios esperados por la población, sobre todo, en términos de los problemas principales del país. Esto significa que si el proceso electoral de 1997 registró menores niveles de confianza y participación es porque, en este caso, la gente parece haber profundizado esa convicción de que la clase política no fue capaz de producir los cambios esperados. Se ha visto, casi al inicio de este trabajo, cómo los partidos políticos obtuvieron sólo un porcentaje mínimo de apoyo de la población en edad de sufragar que, en comparación con las elecciones generales de 1994, representa una reducción en la participación de casi el 14 por ciento (ver Cuadro 1). Por tanto, relacionado con esto, uno de los efectos más notables del aumento del abstencionismo es, lógicamente, la erosión en la capacidad de convocatoria

15. Para ello, las respuestas sobre la confianza en los comicios se convirtieron en una escala del 1 a 4 , en la que se asignó uno de estos valores a cada una de las respuestas: nada de confianza (1), poco de confianza (2), algo de confianza (3) y mucha confianza (4). Así, un promedio cercano al 1 significaría desconfianza en las elecciones, 
de los partidos políticos. En esencia, los partidos políticos perdieron apoyo ciudadano en 1997; pero sería injusto decir que todos los institutos políticos se vieron desgastados. Para poder caracterizar y explicar mejor el fenómeno del abstencionismo es necesario, por consiguiente, identificar de dónde vino ese abstencionismo. Todos los datos disponibles concuerdan en señalar que los mayores "contribuyentes" al absentismo en 1997 fueron los partidos ARENA y Demócrata Cristiano.

\section{La contribución de ARENA y del Partido De-} mócrata Cristiano al abstencionismo de 1997

El abstencionismo, en gran medida, podría atribuirse a la erosión que enfrentaron ARENA y el Partido Demócrata Cristiano, en especial el primero; curiosamente ambos partidos han formado gobiernos en el ciclo político-electoral que comenzó en los años ochenta. De acuerdo con las cifras presentadas en el Cuadro 10, la mayoría de los partidos políticos que contendieron en ambas elecciones (1994 y 1997) para ganar puestos en el parlamento tuvieron que enfrentar pérdidas de apoyo popular en las últimas elecciones. Efectivamente, ARENA, el Partido Demócrata Cristiano (PDC), Convergencia Democrática (CD), Movimiento de Unidad (MU) y el Movimiento de Solidaridad Nacional (MSN), vieron erosionada su capacidad de convocatoria electoral; los únicos partidos que registraron una tendencia contraria y que, por lo tanto, resultaron beneficiados por un aumento de apoyo popular fueron el FMLN y el Partido de Conciliación Nacional. Luego, hay que decir que algunos partidos políticos que participaron en 1994 desaparecieron en las elecciones de 1997; mientras que otros, un número importante de partidos nue-

Cuadro 10

Diferencias de votos emitidos en las elecciones de 1994 y 1997 según partido político

\begin{tabular}{lcrrr}
\hline & \multicolumn{2}{c}{$\begin{array}{l}\text { Número de votos obtenidos } \\
\text { en la elección de diputados }\end{array}$} & \multicolumn{2}{c}{ Diferencia } \\
\cline { 2 - 5 } Partido & 1994 & 1997 & $\mathrm{~N}$ & $\%$ \\
\hline ARENA & 605,775 & 396,301 & $-209,474$ & -34.6 \\
\hline FMLN & 287,811 & 369,709 & $+81,898$ & +22.2 \\
\hline PDC & 240,451 & 93,545 & $-146,906$ & -61.1 \\
PCN & 83,520 & 97,362 & $+13,842$ & +14.2 \\
CD & 59,843 & 39,145 & $-20,698$ & -34.6 \\
\hline MU & 33,510 & 25,244 & $-8,266$ & -24.7 \\
\hline MSN & 12,827 & 7,012 & $-5,815$ & -45.33 \\
\hline MAC & 12,109 & 0 & $-12,109$ & - \\
\hline MNR & 9,431 & 0 & $-9,431$ & - \\
\hline PRSC & 0 & 30,039 & $+40,039$ & - \\
\hline PLD & 0 & 13,533 & $+35,279$ & - \\
\hline PD & 0 & 2,302 & $+13,533$ & - \\
\hline PL & 0 & 132 & $+2,302$ & - \\
\hline MAS & 0 & & +132 & - \\
\hline Total de votos válidos & $1,345,277$ & $1,119,603$ & $-225,674$ & -16.8 \\
\hline
\end{tabular}

Fuente: Elaboración propia a partir de los datos de la Junta de Vigilancia Electoral (1997).

vos, que participaron por vez primera en una elección en 1997, se vieron totalmente favorecidos por un aumento del 100 por ciento de apoyo popular.
Sin embargo, los datos señalan que en 1997 , los partidos que más resintieron el abandono de sus votantes de 1994 fueron ARENA y el Demó-

mientras que el 4 representaría el nivel más alto de confianza en el proceso. El promedio general fue de 2.59, ubicado prácticamente a la mitad de la escala. 
crata Cristiano, tanto por la cantidad de votos potenciales como por el porcentaje que éstos significaban para el partido. De esta manera, cada partido perdió a más de 140 mil electores, lo cual provocó un sensible desgaste en ambos partidos especialmente en el PDC - y obligó a un arreglo en las preferencias partidarias de 1997. Los números con los que se dispone en el cuadro sugieren que este reacomodo consistió en el traspaso de votantes a los partidos nuevos, tanto como a los dos partidos antiguos que aumentaron su caudal (PCN y FMLN), pero que aún así, hubo un número im- portante (cerca del 17 por ciento) que no se desplazaron hacia otra opción política y se quedaron sin votar en las elecciones de 1997.

No es el propósito de este trabajo intentar reconstruir cómo se dieron esos desplazamientos entre los partidos: por quiénes votaron los "desertores" de ARENA y PDC, así como adivinar la procedencia de los nuevos electores del FMLN y PCN, eso probablemente amerite otro trabajo de esta magnitud. Más bien, la intención en este apartado complementario es tratar de identificar de dónde

\section{Cuadro 11}

Personas que no participaron a nivel electoral en 1997 según el partido por el que votaron en 1994

(En porcentajes)

\begin{tabular}{lcccccccc}
\hline & \multicolumn{7}{c}{ Partido por el que votó en 1994 } \\
\cline { 2 - 8 } ¿Votaron en el 97? & Ninguno & ARENA & FMLN & PDC & CD & PCN & Otros \\
\hline Probablemente no votaron & 61.3 & 26.4 & 3.9 & 4.4 & 0.8 & 2.3 & 0.5 \\
\hline
\end{tabular}

Fuente: Elaboración propia a partir de la base de datos del IUDOP.

provienen los "nuevos abstencionistas" de los comicios de 1997. En este punto, los datos no son tan concluyentes pero pueden dar una pista de la magnitud del impacto de desgaste de algunos partidos sobre el abstencionismo de 1997.

Con los resultados de la encuesta preelectoral realizada por el IUDOP en febrero de 1997 y cruzando los datos acerca de la intención de voto en las elecciones del 94 con las personas que dijeron que no tenían partido alguno de preferencia -como indicador predictivo de abstencionismo- se construyó el Cuadro $11^{16}$. Según dicho cuadro, la mayor parte de las personas que no asistieron a votar en 1994 (el 61.3 por ciento), tampoco lo habrían hecho en 1997; sin embargo, el resto de personas que no votaron en el 97 sí lo habrían hecho en el 94: el 26.4 por ciento votó por ARENA; el 3.9 por ciento lo hizo por el FMLN; el 4.4. por ciento por el Partido Demócrata Cristiano y el resto eligió otros partidos. En otras palabras, las cifras sugie- ren que de los partidos que compitieron en el 94 ARENA habría aportado el mayor porcentaje de abstencionismo del 97 -sólo después de aquéllos que históricamente no suelen votar-; esto es mucho más de lo que pudo haber cedido el Partido Demócrata Cristiano, que aparece con el siguiente porcentaje más alto, o cualquier otro partido contendiente en el 94.

Dado el carácter especulativo de estos datos, no es posible asumir que los porcentajes expuestos en el Cuadro 11 son concluyentes en términos precisos; más bien, pueden ofrecer una idea de dónde viene la mayor parte del absentismo para los recientes sufragios municipales y legislativos. En todo caso, lo que parece bastante claro es que el absentismo de las elecciones de 1997 se nutrió en buena medida de los desencantados del partido gobemante; esto no niega la posibilidad de que algunos de esos desencantados hayan pasado a apoyar a otros institutos políticos. Sin embargo, releyendo

16. Lamentablemente, la encuesta de evaluación poselectoral no recogió las preferencias políticas que tenían los ciudadanos en el proceso electoral de 1994, para poder cruzarla con la participación ciudadana de 1997. Por tal motivo se acudió a los datos de la úlima encuesta pre-electoral que pueden brindar una aproximación al fenómeno. 
los datos del Cuadro 11 se podría pensar que los votantes desilusionados con el Partido Demócrata Cristiano son quienes habrían registrado el mayor porcentaje de desplazamiento a otros partidos. Es decir, las evidencias que ofrecen las encuestas apuntan a que gran parte del desgaste del partido ARENA se mostró en la renuncia de una gran proporción de los salvadoreños en asistir a votar - aunque es muy probable que otros ciudadanos hayan conmutado hacia otros partidos-; pero, por otro lado, el desgaste del Partido Demócrata Cristiano nutrió menos al abstencionismo y más a otros partidos (posiblemente los nuevos institutos que participaron en el 97: PRSC, PLD y PD).

Lo anterior constituye un aspecto que explica y aporta más sentido a los argumentos sobre abstencionismo que se han venido manejando en este trabajo. Sin duda, el abstencionismo no es un fenómeno nuevo en la dinámica electoral salvadoreña; la expresión del mismo en el proceso eleccionario de 1997 no es única pero es particular. Lo peculiar radica en el señalamiento por parte de los ciudadanos de que una de las principales razones para la abstención radica en la falta de opciones partidistas que sean viables. Nunca antes había habido tanto abstencionismo, y también nunca antes se había insistido tanto en la falta de confianza institucional. Se ha visto que esto se encuentra relacionado con la percepción de que la clase política no ha sido capaz de generar los cambios esperados en la realidad y que ello ha profundizado los niveles de desconfianza en los partidos y el sistema político. Esto tiene sentido si se advierte que los cambios se esperan de quien tiene el poder, es decir, del partido gobernante. Si la población piensa que no han habido los cambios sustanciales que se esperaban, es muy probable que vean como principal responsable al partido del gobierno, al que algunos de ellos eligieron para representarles y cumplir con sus demandas. Así, los ciudadanos que antes confiaban en los partidos políticos y en el sistema como efecto de la simpatía que les unía con su partido favorito, ahora se encuentran que su partido de referencia no ha sido capaz de responder a sus expectativas, y ello contribuye a sembrar la duda no sólo sobre su partido sino también en el resto de instituciones políticas. En ese momento, muchos ciudadanos caen en la cuenta de que tam- poco confían en el resto de instituciones políticas como para trasladarles totalmente su apoyo, dado que las mismas no son capaces de articular un proyecto político atractivo o viable para los ciudadanos en las condiciones que son permitidas por el aparato electoral.

En otras palabras, en su mayoría, este absentismo "inesperado" de 1997 se produciría a partir de la evaluación que los antiguos votantes del partido en el gobierno han hecho de su gestión política. Tal valoración no sólo impacta al partido mismo sino también a todos los elementos contiguos a él: partidos políticos contrincantes, sistema electoral, etcétera; haciendo que el desencanto y la desconfianza se irradien hacia todo el aparato. Esta aseveración parece dar mucha importancia al partido oficial. La verdad es que la tiene, dada la forma en que los partidos gobernantes llegan a concentrar poder e influencias en un sistema político como el salvadoreño.

Esto quiere decir que el desgaste de cualquier otro partido político no vinculado directamente con el gobierno probablemente no hubiese marcado tanto el absentismo del 97 (podría ser el caso del Partido Demócrata Cristiano). Ello por un principio lógico: un partido que no tiene poder no defrauda, pues no tiene posibilidades de cumplir promesas y de actuar significativamente sobre la realidad. Por ello, las probabilidades de desencanto con un partido aumentan en la medida en que dicha organización acumule más poder. El que un partido sin mayor autoridad disguste a sus electores por su comportamiento habitual u ocasional probablemente no afecta más que al mismo partido al provocar el descenso de su apoyo. Pero si el instituto político en cuestión tiene poder y representa la conducción política del país, cualquier cosa que haga tendrá un impacto sobre el sistema. Eso parece haber sucedido en las elecciones de 1997 con el partido ARENA.

¿Cómo queda entonces la postura de los partidos contendientes, sobre todo del FMLN, frente a la oportunidad de atraer nuevos votantes hacia sí y evitar el abstencionismo? Ciertamente, el FMLN se benefició del desgaste del partido gobernante y hasta cierto punto se vio favorecido por el paso de antiguos votantes de ARENA $^{17}$, pero esto, aunque importante, no fue masivo y el grupo más grande

17. Una explicación más detallada sobre este tema puede encontrarse en el trabajo de José Miguel Cruz: Elecciones y pensamiento social: opinión pública en los comicios 97, que será publicado por FLACSO - se encontraba en prensa en el momento de terminar este trabajo. 
de desertores de Alianza Republicana Nacionalista se quedó sin votar. ¿Cómo se explica entonces, en el caso de ARENA, la ausencia de un traspaso masivo a otros partidos, como parece haber sucedido en el PDC? Hay razones para pensar que la respuesta está en el contexto de enfrentamiento polarizado que domina a las dinámicas electorales de la posguerra. En un estado de polarización política, en la cual domina el enfrentamiento de dos visiones políticas antagónicas, se crea una dinámica en la cual sólo dos grandes polos representan posibilidades, el resto de instituciones prácticamente está fuera de atraer adeptos porque no son vistas con la capacidad de remontar la fuerza de los "grandes" partidos. Se es derecha o se es izquierda, e inclusive el centro - con sus partidos "pequeños"- es visto bajo el cristal de los polos: centro-derecha, centro-izquierda. En una situación así, el llamado centro no se concibe.

Defraudados por uno de esos partidos polares, los ciudadanos deben enfrentar altemativas que no suelen ser de su agrado: por un lado, deben enfrentar el hecho de que la utilidad de su participación electoral sólo puede mantenerse si votan por el partido contrincante, algo que a los más alineados políticamente les ocasiona mucho conflicto moral; por el otro, se encuentran frente a la realidad de tener que votar por un partido que en realidad no tiene ninguna posibilidad de triunfo frente a los más grandes; finalmente, deben enfrentar la alternativa de abstenerse como una opción casi obligada frente a la resistencia de escoger cualquiera de las anteriores. Es muy posible que esto haya sucedido con varios de los antiguos correligionarios del partido oficial. Convencidos de que no votarían por ARENA a causa de su desilusión, estas personas se enfrentan a la disyuntiva de tener que votar por el FMLN, un partido ideológicamente -y muchas veces emocionalmenteopuesto a su forma de pensar; o, en su defecto, por alguno de los numerosos partidos pequeños que, aunque puede satisfacer su posición político-ideológica, no ofrece las garantías de un "voto útil". En estas circunstancias muchos decidieron no votar.

Ahora bien, no hay que olvidar que esta dinámica explica el abstencionismo inédito que tomó lugar en 1997 y que hizo aumentar, de manera significativa, la cuota de personas que se negaron a participar electoralmente. Pero en el fondo, lo que sucedió es que se exacerbaron las condiciones que

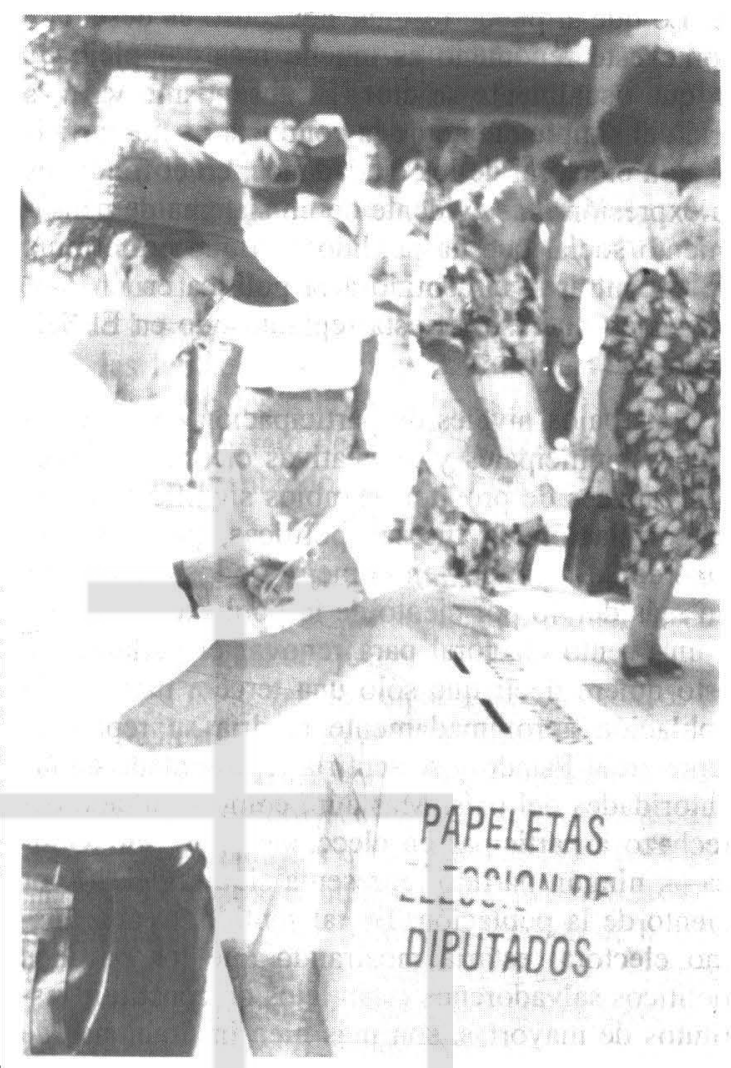

desde hace cierto tiempo provocan que muchos ciudadanos no emitan su voto. La desconfianza en el sistema, el desencanto y la falta de identificación partidaria se generalizaron aún más, lo que produjo votaciones en las cuales intervino sólo la tercera parte de la población. Hasta 1997, mucha gente pensaba que el abstencionismo no era un problema serio para las elecciones y el proceso de transición política salvadoreña. Lo que sucedió el 16 de marzo anterior puso en evidencia que el problema de la participación ciudadana no sólo puede afectar a un partido político sino a todo el sistema, y que niveles $\tan$ bajos de apoyo popular pueden llegar a convertirse en un problema de representatividad y legitimidad política (ver Cuadro 2), en una época de transición incierta como la que vive el país en la actualidad.

\section{Conclusiones}

No es nada nuevo afirmar que el abstencionismo es un problema para el sistema político salvadoreño, sobre todo a causa de la etapa de transición en la que se encuentra la sociedad actualmen- 
te. Lo que sí puede resultar novedoso es descubrir cómo este fenómeno es mucho más complejo de lo que usualmente se cree. El absentismo va más allá del simple efecto de la conducta de no-participación electoral de los ciudadanos; en el fondo, es la expresión más evidente de un sistema de pensamiento social que ha perdido $\longrightarrow$ que no termina de encontrar- el sentido a la política en un momento en que ésta se está replanteando en El Salvador.

Los bajos niveles de participación en las elecciones municipales y legislativas ciertamente fueron capaces de producir cambios significativos en la correlación de fuerzas políticas, pero esto se hizo con el apoyo —en el mejor de los casos- de no más del $\mathbf{4 0}$ por ciento de la población. De cara a un evento electoral para renovar el parlamento, esto quiere decir que sólo una tercera parte de la población aproximadamente tendría su representante en el Estado y se sentiría representado en las autoridades del país. Más aún, como resultado del rechazo a participar en elecciones -y en política-, ningún partido representa siquiera el 20 por ciento de la población. En tal sentido, el absentismo electoral estaría mostrando que los partidos políticos salvadoreños están lejos de constituir institutos de mayorías, son más bien instituciones de minorías, grandes minorías en algunos casos. La institución de las mayorías es entonces el absentismo.

Estos porcentajes de apoyo tan bajos a los partidos no son por sí mismos un problema necesariamente. En algunos ccontextos esto podría obligar a que los partidos reúnan esfuerzos para conducir conjuntamente a la sociedad a criterio y beneficio de todos, sobre todo de quienes no votan -aunque sea como una forma de lograr votos en el futuro. Lo perjudicial es, más bien, que las instituciones políticas se comporten como si esos pequeños porcentajes de preferencias electorales representasen el apoyo de toda la población y, en consecuencia, actúen pensando más en imponer su visión particular de la realidad a toda la sociedad y no en nutrirse de la misma para responder a los intereses de todo el país.

Los datos de las encuestas de opinión pública revelan que la mayor parte del abstencionismo no se explica fundamentalmente por los errores o fallas del sistema electoral; más bien se explica por la forma de funcionamiento del sistema político. Los salvadoreños, consciente e inconscientemente, atribuyen la (su) falta de participación electoral, en 1997 y en otras elecciones, a la poca utilidad que han descubierto de los procesos electorales y a la poca confianza que les merecen los aspectos relacionados con la política. Esto no es algo novedoso, ha sido planteado en otros trabajos y en otros momentos (Baloyra-Herp, 1995; Cruz, 1994); lo novedoso que ha buscado obtener este trabajo de investigación es demostrar cómo todos esos aspectos se encuentran íntimamente vinculados entre sí, de tal manera que es imposible entender este fenómeno sin considerar la forma en que los ciudadanos ven la realidad salvadoreña y sus problemas, $y$ la forma en que los ciudadanos evalúan al gobierno y a los partidos políticos.

En resumen, el abstencionismo sería producto de una profunda falta de confianza en el sistema político con todos sus aspectos. Este desencanto estaría producido por la percepción de que a pesar de los repetidos eventos electorales, de los sucesos políticos - como los acuerdos de paz- y del relevo de los distintos gobiemos, la situación del país y, en especial, las condiciones de vida de las mayorías no han mejorado substantivamente. Así, los absentistas más comunes serían las personas que se encuentran en desventaja social: los pobres y marginados. Decir que el absentismo es la institución más apoyada por las mayorías de este país no sólo tiene un sentido cuantitativo, sino sobre todo tiene una justificación cualitativa. En las elecciones de 1997, el abstencionismo se habría incrementado como producto de la sensación de significativos sectores poblacionales de que el partido oficial no había sido capaz de llenar las expectativas creadas luego del fin de la guerra. Este desencanto, por consiguiente, no sólo afectó al partido como tal; bajo un contexto de polarización y de endeble institucionalización, también afectó al resto de partidos que tampoco eran vistos con la capacidad necesaria para promover los cambios y al sistema político en su conjunto.

Reflexionando ya para finalizar, el problema entonces no está sólo en el sistema electoral, sino sobre todo en el sistema político, pues es el que, a juicio de la ciudadanía, no ha sido capaz de ofrecer alternativas de resolución a los problemas principales del país. En esencia, ello se refiere a las posibilidades del desarrollo, de mejoramiento del país. De ahí que, probablemente, la mejor forma de enfrentar este problema no sea mediante el impulso de reformas que están circunscritas al siste- 
ma electoral - concentrando con ello los esfuerzos sólo en aspectos muy puntuales como el registro electoral, los mecanismos de inscripción de partidos o la posesión del documento único de identidad-, sino enfrentando e impulsando un debate que lleve a reformas en el carácter de los partidos mismos y el papel de éstos en la posguerra. No se quiere decir que las reformas electorales no sean importantes, pero tal y como lo intentan manejar los políticos puede convertirse un chivo expiatorio, de los males de todo el sistema. Por lo tanto, concentrarse sólo en el aspecto electoral sin revisar lo político podría ser un grave error, porque el fundamento de la problemática no está ahí. Estaría, entre otras cosas, en la forma en que el sistema político y los partidos dentro de él "aprendieron" a funcionar.

El punto es que básicamente el sistema político contemporáneo, con sus partidos más grandes, sigue funcionando con la dinámica en la cual se creó: bajo condiciones de guerra y, por tanto, de extrema polarización social. En tal sentido, los partidos que ahora representan los institutos políticos más fuertes $\multimap$ dicho más precisamente, los menos débiles-, se crearon en tiempos de guerra y como cristalizadores de algunos sectores de una sociedad enfrentada consigo misma, surgieron para defender ciertos intereses o cierta visión ideológica. Sin embargo, con el fin de la guerra y el derrumbamiento del bloque socialista, estos partidos perdieron el sentido que en su momento les hizo formarse y crecer; el problema es que no han sido capaces de replantearse en la práctica su nuevo papel en las actuales condiciones. El problema es que aún se siguen concibiendo a sí mismos como los defensores de sectores e intereses -que asumen como las mayorías - y no como instrumentos de conducción democrática para construir en conjunto a la sociedad salvadoreña de la posguerra.

¿Quiere decir esto que los partidos actuales deben desaparecer para dar lugar a la generación de instituciones auténticas de la posguerra? Es difícil contestar esto porque quizás no sea la pregunta más adecuada. Lo que parece la respuesta más apropiada es la siguiente: Lo importante no es la creación de más o menos partidos, o la desintegración de los ya existentes -esto es más bien una cuestión de forma-; lo importante, lo de fondo, es que los partidos deben replantearse fundamentalmente su papel en la nueva era; algo que proba- blemente hayan hecho algunos con más o menos éxito a nivel teorético pero que no lo han asumido en la práctica. Y no lo han hecho porque, en parte, no han encontrado los espacios para hacerlo en un sistema polarizado, y porque no se han atrevido a apostar por otra forma de hacer política que la que aprehendieron durante el conflicto civil salvadoreño. Al final, las coyunturas electorales evidencian de que los partidos políticos terminan sucumbiendo a las tentaciones de seguir haciendo la guerra -porque esto les trajo beneficios en el pasadoy abandonan el reto de hacer la paz, algo que podrian hacer intentando construir una sociedad para todos.

El problema del abstencionismo es el problema de una sociedad civil que se niega a participar con las actuales reglas del juego. Probadas las opciones disponibles no se puede culpar a los ciudadanos de indiferencia si las clases políticas han sido incapaces de responder y dar cuentas a los ciudadanos cuando éstos las han pedido y exigido. El reto de participación electoral para las elecciones de 1999 pasa por superar la apatía contemporánea generalizada, y mientras los partidos continúen pensando de la misma forma en que lo han hecho hasta ahora, el sistema político salvadoreño está condenado a tocar fondo y deslegitimarse por completo.

\section{Referencias bibliográficas}

Artiga-González, Alvaro. "Efectos de los sistemas electorales en El Salvador", Realidad, No. 58. El Salvador, 1997, pp. 333-346.

Baloyra-Herp, Enrique A. "Elections, civil war, and transition in El Salvador, 1982-1994: A preliminary evaluation", en Mitchell A. Seligson y John A. Booth (Eds.): Elections and democracy in Central America Revisited. Chapel Hill: The University of North Carolina Press, 1995.

Coleman, Kenneth; Cruz, José Miguel; Moore, Peter. "Retos para consolidar la democracia en El Salvador", Estudios Centroamericanos (ECA), No. 571-772, El Salvador, 1996, pp. 415-440.

Cruz, José Miguel. “Las encuestas de opinión pública y las elecciones de 1997", en: El Salvador. Elecciones 1997, editado por FUNDAUNGO, San Salvador: Fundación Dr. Guillermo Manuel Ungo, 1997.

Cruz, José Miguel. "El proceso electoral de 1994 en la opinión pública salvadoreña", en: El proceso electoral 1994, editado por FLACSO, San Salvador: Facultad Latinoamericana de Ciencias Sociales, 1995.

Cruz, José Miguel. "Ausentismo en las elecciones: algunas hipótesis y reflexiones desde las encuestas", Es- 
tudios Centroamericanos (ECA), No. 545-546, El Salvador, 1994, pp. 274-285.

Dirección de Información. "Encuesta de Hogares de Propósitos Múltiples (EHPM)", San Salvador: Ministerio de Coordinación del Desarrollo Económico y Social, 1994.

Dirección General de Estadísticas y Censos, Fondo de Población de las Naciones Unidas y Centro Latinoamericano de Demografía. Proyección de la Población de El Salvador, 1995-2025, San Salvador: Ministerio de Economía, 1996.

Gobierno de El Salvador (GOES) y Programa de las Naciones Unidas para el Desarrollo (PNUD). Informe sobre índices de desarrallo humano en El Salva. dor, San Salvador, 1997.

Instituto Universitario de Opinión Pública (IUDOP). "Encuesta sobre el proceso electoral de 1997", Serie de informes, $N^{\circ}$ 61, San Salvador, 1997a.

Instituto Universitario de Opinión Pública (IUDOP). "La jornada electoral del 16 de marzo en San Salvador. Encuesta de salida de urnas", Boletín de prensa, XII, 2, San Salvador, $1997 c$.

Instituto Universitario de Opinión Pública (IUDOP). "Campaña electoral, desconfianza e interés", Proceso, No. 749, San Salvador, 1997c, pp. 11-12.
Instituto Universitario de Opinión Pública (IUDOP) "Sondeo de evaluación sobre el tercer año de Calderón Sol y evaluación post-electoral", Serie de informes, $N^{\circ} 63$, San Salvador, $1997 d$.

Instituto Universitario de Opinión Pública (IUDOP). "Encuesta de evaluación política de 1996", Serie de informes, $\mathbf{N}^{\circ}$ 60, San Salvador, 1996.

Instituto Universitario de Opinión Pública (IUDOP). "La religión de los salvadoreños", Estudios Centroamericanos (ECA), No. 563, San Salvador, 1995a, pp. 849862.

Instituto Universitario de Opinión Pública (IUDOP). "Encuesta sobre el sistema político salvadoreño", Serie de informes, NN 51, San Salvador, $1995 b$.

Instituto Universitario de Opinión Pública (IUDOP). "La opinión de los salvadoreños sobre las elecciones. La última encuesta pre-electoral", Estudios Centroamericanos (ECA), No. 545-546, San Salvador, 1994, pp. 165-194.

Junta de Vigilancia Electoral. Resultados estadisticos de las elecciones de 1994 y 1997, San Salvador, 1997.

Tribunal Supremo Electoral. "De los ciudadanos aptos para ejercer el sufragio", publicado en La Prensa Gráfica, 16 de marzo de 1997. 